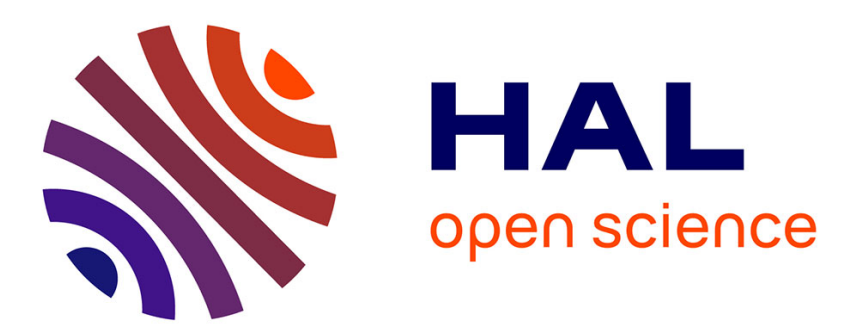

\title{
Community composition predicts photogrammetry-based structural complexity on coral reefs
}

J. Carlot, A. Rovère, E. Casella, D. Harris, C. Grellet-Muñoz, Y. Chancerelle, E. Dormy, L. Hédouin, V. Parravicini

\section{To cite this version:}

J. Carlot, A. Rovère, E. Casella, D. Harris, C. Grellet-Muñoz, et al.. Community composition predicts photogrammetry-based structural complexity on coral reefs. Coral Reefs, 2020, 39, pp.967-975. 10.1007/s00338-020-01916-8 . hal-02715266

\section{HAL Id: hal-02715266 \\ https://hal-univ-perp.archives-ouvertes.fr/hal-02715266}

Submitted on 26 Nov 2020

HAL is a multi-disciplinary open access archive for the deposit and dissemination of scientific research documents, whether they are published or not. The documents may come from teaching and research institutions in France or abroad, or from public or private research centers.
L'archive ouverte pluridisciplinaire HAL, est destinée au dépôt et à la diffusion de documents scientifiques de niveau recherche, publiés ou non, émanant des établissements d'enseignement et de recherche français ou étrangers, des laboratoires publics ou privés. 


\section{Community composition predicts photogrammetry-based structural}

\section{2 complexity on coral reefs}

3

4

J. Carlot ${ }^{1-2^{*}}$, A. Rovère ${ }^{3-4}$, E. Casella ${ }^{3-4}$, D. Harris ${ }^{5}$, C. Grellet-Muñoz ${ }^{1-3}$, Y. Chancerelle ${ }^{1-2}$, 5

E. Dormy ${ }^{6}$, L. Hedouin ${ }^{1-2}$, V. Parravicini ${ }^{1-2}$

6

$7 \quad$ PSSL Université Paris: EPHE-UPVD-CNRS, USR 3278 CRIOBE, BP 1013, 98729 Papetoai,

8 Moorea, French Polynesia

9 2'Laboratoire d'Excellence « CORAIL »

$10{ }^{3}$ Centre for Marine Environmental Sciences (MARUM), Bremen University, Bremen,

11 Germany.

$12{ }^{4}$ Leibniz Centre for Tropical Marine Research, Bremen, Germany.

$13{ }^{5}$ The University of Queensland, School of Earth and Environmental Sciences, Brisbane,

14 Queensland, Australia.

$15{ }^{6}$ Department of Mathematics and Applications, CNRS UMR 8553, Ecole Normale Supérieure,

16 Paris, France

17

18 Keywords

19 Coral Complexity - Rugosity measures - Photogrammetry - Reef ecology - Modeling

20

21 *Corresponding author: Jérémy Carlot,

PSL Research University

EPHE-UPVD-CNRS

24

USR 3278 CRIOBE

25

BP 1013, 98729 Papetoai, Moorea, French Polynesia

26

Laboratoire d'Excellence « CORAIL »

27

E-mail: Jeremy.carlot@hotmail.fr 
Abstract

The capacity of coral reefs to provide ecosystem services, to keep their diversity and 30 their productivity are related to their three-dimensional structural complexity. This parameter 31 is also correlated to total fish biomass, to the general reef resilience to external stresses and to 32 their ability to dissipate wave energy. However, information on structural complexity (also 33 defined as reef rugosity) has been uncommonly assessed in historical monitoring programs, 34 with the result that the long-term trend of this variable is generally unavailable. In this study, 35 we show that it is possible to predict and hindcast the three-dimensional complexity of coral 36 reefs by combining photogrammetry, statistical modeling and historical benthic community 37 data. We calibrated a lasso generalized linear model to predict structural complexity obtained 38 by 57 photogrammetry transects recorded at 13 sites around the island of Moorea (French 39 Polynesia). Our model was able to predict structural complexity with high accuracy (cross40 validated $\mathrm{R}^{2}=0.81 \pm 0.12$ ). We then used our model to hindcast historical trends in $3 \mathrm{D}$ 41 structural complexity using community composition data collected in Moorea from 2004 to 42 2017. The temporal analysis highlighted the dramatic effect of a crown-of-thorns outbreak in 43 2006-2009 and Cyclone Oli in 2010. These two events together reduce coral cover from $\approx 50 \%$ 44 to almost zero. Our model captured these effects, confirming the possibility to predict structural 45 complexity on the basis of assemblage composition. 


\section{Introduction}

Global concerns are emerging about the increasing frequency of mass mortality of corals associated to coral bleaching events (Van Oppen and Lough 2009; Heron et al. 2016; Hughes et al. 2017). These disturbances are associated to severe habitat destruction that reduces the structural complexity (i.e., flattening) of coral reefs (Newman et al. 2015). Structural complexity is the three-dimensional spatial arrangement of an ecosystem (McCormick 1994; Chazdon 2014), which is largely due to the growth form and distribution of hard coral. According to the habitat heterogeneity hypothesis (MacArthur and Wilson 1967), the more complex the structure of an ecosystem, the greater the diversity and abundance of associated organisms. On coral reefs, the 3D structural complexity of the habitat is correlated to the biomass and diversity of fish (Willis and Anderson 2003; Gratwicke and Speight 2005; Alvarez-Filip et al. 2009; Rogers et al. 2014), to the reef capacity to recover from disturbance (Graham et al. 2015), but also to the reef ability to dissipate wave energy, thus protecting the shoreline from extreme inundations (Harris et al. 2018). Broad-scale declines in the complexity of coral reefs have been observed both in the Caribbean and the Pacific as a result of both human impacts and climate changes (Hoegh-Guldberg 1999; Hughes et al. 2003; Hoegh-Guldberg et al. 2007; Perry et al. 2018). Despite the well-known important relationship between structural complexity, ecological diversity, abundance and biomass, information on structural complexity is sparse in monitoring programs with the result that long-term trends for this variable are virtually unknown (Graham et al. 2015).

Methods to measure structural complexity (often referred as rugosity, in particular in older literature) on coral reefs first arose in the 70' in articles by Risk (1972) and Hobson (1972). These authors defined three criteria for measuring complexity: 1) the measure had to be easily understandable, 2) it had to be measurable during the fieldwork and, 3) it should be comparable. In early studies, it was proposed that rugosity could be recorded by draping a steel 
and the planar distance between the ends of the chain. The higher the ratio, the more complex the substratum (Hill and Wilkinson 2004; Graham and Nash 2013). Despite the ease of use of such metric, laying a chain represents a bi-dimensional measure which does not capture the full complexity of complex three-dimensional (3D) habitats such as coral reefs. Although some time-consuming 3D metrics have been proposed in the past (e.g. Parravicini et al. 2006), the recent progress in underwater photogrammetry are finally affording researchers the opportunity to capture the three-dimensionality of coral reefs. For example, Friedman et al. (2012) started to use a georeferenced survey work and each includes a downward-looking camera pair with a baseline of approximately $7 \mathrm{~cm}$, pixel resolution of $1360 \times 1024$ to define rugosity. Others authors like Burns et al. (2015) were using these new advances for defining the rugosity about a transect and extract a complexity index at the species level for 6 species. Leon et al. (2015), defined three roughness parameters, namely the root means square height, tortuosity (i.e. rugosity) and fractal dimension, and were derived and compared in order to asses which one better characterizes reef flat roughness. Naughton et al. (2015) succeed with an accuracy never equaled to define maps of community structures between taxa. Some writers have even pushed the boundaries to measure the small-scale three-dimensional features of a shallow-water coral reef thanks to drone (Casella et al. 2017). Thus, a plethora of works have emerged asking several authors about the chain-tape future (Storlazzi et al. 2016). However, whatever the metric employed (chain-tape or photogrammetry methods), there is still no clear evidence concerning what is driving structural complexity. Some authors claim that it is driven by the presence of some branching species like the Acropora spp. and thus the overall coral cover would not matter (Aronson and Precht 2006; Alvarez-Filip et al. 2009, 2011). Others have found that coral cover is significantly and highly correlated to the rugosity (Halford et al. 2004; Graham and Nash 2013) or species composition (Richardson et al. 2017). But in both cases, there is a common consensus for admitting coral drives complexity which could be used for rebuilding past rugosities. 
In this study, we combined statistical modeling to 3D reef transects reconstructed using

99 photogrammetry in order to test the potential to predict coral reef structural complexity on the 100 basis of benthic community composition. We study the reefs of Moorea (French Polynesia) where, using benthic communities time series we back-calculate reef structural complexity. We were able to retrace two relevant episodes of habitat destruction: the Acanthaster planci outbreak of 2006-2009 and cyclone Oli of 2010.

Material and Methods

\section{Study area}

Moorea is a tropical volcanic island of volcanic origin, located in the Pacific Ocean between $17.4714^{\circ}$ and $17.6058^{\circ}$ South and $149.7522^{\circ}$ and $149.9269^{\circ}$ 'West. The island is shaped as a triangle with a perimeter of $61 \mathrm{~km}$ and coastlines facing north, southwest and southeast (Fig. 1). The island is encircled by a coral reef, that is 500 to $700 \mathrm{~m}$ wide; the only exception to this pattern is the Northeast extremity where the lagoon width is limited to few tens of meters. Moorea is exposed to Northwest winds from January to March. Tides are semidiurnal with an amplitude of less than $0.3 \mathrm{~m}$ (Chazottes et al. 1995; Leichter et al. 2013). The swell direction is from southwest to northeast during the whole year. Acanthatster planci outbreak, which reduced coral cover from 50\% to $10 \%$ (in 1979; Berumen and Pratchett 2006) and from 50\% to less than 10\% (in 2006; Lamy et al. 2016). Abiotic disturbances also impacted Moorea island, with main cyclones recorded in 1991 (Wasa) and 2010 (Oli). The impact of Wasa reduced the coral cover by $5 \%$ to over $20 \%$ across all the island.

121 In contrast, coral cover was reduced to lower than $5 \%$ by Cyclone Oli (Lamy et al. 2016;

122 Adjeroud et al. 2018) (Fig. 2). 
In Moorea, a total of 57 photogrammetric transects were surveyed in end-of-2015 -

126 beginning-of-2016, at three different sites: Tiahura (North Coast, 21 transects); Haapiti

127 (Southwest coast, 20 transects) and Temae (Southeast coast, 16 transects) (Fig. 1). Each transect

128 consisted of swaths of $20 \mathrm{~m}$ length and $2 \mathrm{~m}$ width and all transects were carried out in the outer

129 reef, between 5 and $8 \mathrm{~m}$ depth. Each transect was set up fixing on the bottom a $2 \mathrm{~m}$-long chain

130 and, perpendicularly to it, a $20 \mathrm{~m}$-long metered tape. A diver swam $\approx 2 \mathrm{~m}$ above the sea-bottom,

131 maintaining the swimming speed as constant as possible and collecting images with a GoPro

132 Hero camera pointed towards the sea-bottom. The camera was set to collect photos (12

133 megapixels) in time-lapse mode (2 pictures per second). For each transect, we collected

134 approximately 200 photos with a forward overlap of $\approx 90 \%$, with the diver swimming over the

135 length of the entire transect four times to allow optimal side overlap. After the collection of the

136 photos, the diver noted the depth of each extremity of the chain and metered tape to use them

137 in the photogrammetric process as Ground Control Points (GCPs). In the case of an on-the-job

138 self-calibration, the camera calibration is derived from image coordinates measured in the

139 mapping photography and including the camera calibration parameters as unknowns in a self-

140 calibrating bundle adjustment (Harwin et al. 2015).

141 The set of photos and the GCPs collected were then used as input to Agisoft Photoscan

142 (www.agisoft.com), a photogrammetry software based on the Structure from Motion (SfM)

143 method (Ullman 1979; Westoby et al. 2012). We used Agisoft to build the orthophotomosaic

144 and the Digital Elevation Model (DEM) of each transect, with the same procedure explained

145 by Storlazzi et al. (2016). Details of the photogrammetric process are shown in the Annex S1.

146 Subsequently, we imported the DEM in ArcGIS v10.2 and calculated the reef rugosity by

147 dividing the surface of the DEM area by the area of its planar projection (approximately $40 \mathrm{~m}^{2}$ )

148 (Fig. 3). For the 57 transects, we estimated an average horizontal error of $0.1 \pm 0.06 \mathrm{~m}$ and

149 average vertical error of $0.04 \pm 0.04 \mathrm{~m}$, internal to the reconstructed model. Only the vertical error 
150 had an influence on the estimation of rugosity, but given the range of the error, it was considered 151 negligible.

152

153

154

155

156

157

158

159

160

161

162

163

164

165

166

167

168

169

170

171

172

173

174

175

\section{Benthic community description and assessment}

The orthophotomosaics were imported into Coral Point Count, which was used with an Excel extension v4.1 (Kohler and Gill 2006). We assessed the benthic cover placing 100 random points on the photomosaic and described 8 distinct benthic cover categories (Table 1). A second dataset was used according to the CRIOBE surveys from 2004 to nowadays and consists of $25 \mathrm{~m}$ point intercept transects data collected at 13 sites around the island across three habitats (fringing reef, back reef, outer reef) and using the same benthic categories (Fig. 1). This classification is based on the guideline of the monitoring program created by SO CORAIL (http://observatoire.criobe.pf/CRIOBEData/), the coral reef observation program of the French National Institute for Earth Sciences and Astronomy (INSU). These categories enabled us to back-calculate structural complexity on time series data from Moorea. For matching both datasets according to the habitat, only the outer reef was selected.

\section{Statistical analysis}

Our main goal was to calibrate a model that predicts structural complexity according to the benthic community composition. Since benthic community cover is expressed as percentages, we preferred not to use them as predictor variables as they are heavily correlated, and collinearity would have been high. We preferred to build a database that include the time series data and our photogrammetry transects without transforming the data to perform multivariate analysis. Thus, the Euclidean distance could be used to conduce a Principal Component Analyses (PCA). The first five orthogonal axes (accounted for more than $75 \%$ of the variance) were then extracted to be used as predictor variables in the model. A lasso generalized linear model has been conducted to predict coral reef structural complexity 
176 according to the 5 PCA axes. A 10-Fold cross validation was done and a step AIC procedure

177 defining the best model was applied. Because the 57 transects were measured at the same depth,

178 those transects were pooled together rather to apply a mixed model due to the lack of the data,

179 making us benefit from a solid robustness. The best model selected kept only 3 PCA 180 dimensions. According to the $\mathrm{k}$-fold analysis, $\mathrm{k}^{2}$ were obtained giving a necessary uncertainty

181 for the model. This method appears more meaningful estimate than classical $\mathrm{R}^{2}$ when the model

182 has to be used for predictions. The lasso generalized linear model was then applied to time

183 series data to back-calculate structural complexity and to test whether our model was able to 184 detect drops of structural complexity due to the major perturbations.

185 The PCA data for the time series in Moorea were used to produce PCA plots and define 186 the long-term tendencies in order to descriptively assess the entity of the effect of the 187 Acanthaster planci outbreak (2006-2009) and the Oli cyclone (2010) on benthic communities. 188 An ANOVA was then applied with the aim to define several bunches of similar years according 189 to the PCA axes. To match those years with each other, a Tukey post-hoc analysis was 190 conducted and a matrix of results was elaborated. Finally, special attention has been given about 191 the Acropora spp. cover, Pocillopora spp. cover and rugosity index in 2004 (pre-disturbance 192 year, with the high percent cover of corals) and 2017 (post-disturbance year, with the high 193 percent cover of corals) to define a potential resilience or recovery (Table S1).

\section{Results}

196 The analysis of time series revealed that coral diversity was higher in 2004 with a 197 percent cover of corals (CC) of 44.08\% (Fig. 4). The CC decreased from 2004 to 2010 down 198 to a minimum of $3.62 \%$, which corresponds to the event of Cyclone Oli. After the cyclone 199 passed, the coral cover increased over time until the end of the series (2017) with a final value 200 of $42.77 \%$. In 2004 the coral reefs of Moorea also showed a greater diversity of coral 201 morphology (massive, branching in general, columns and encrusting). The assemblages 
remained fairly stable despite a slow decline of the $\mathrm{CC}$ the first 2 years $\left(\mathrm{CC}_{2004}=44.08 \%\right.$ to

$203 \mathrm{CC}_{2006}=40.62 \%$ ). Then, a first Crown-Of-Thorns Starfish (COTS) outbreak was reported in 204 early 2006 (Kayal et al. 2012) and continued until 2009. The following year, cyclone Oli hit the 205 island further decreasing the CC. After these events and until 2014, the substrate consisted of 206 rubble and cobbles. From 2015, the CC recovered to a state similar to that of 2004 . However, 207 compared to 2004, the coral cover in 2017 was dominated by Pocillopora spp. (20.10 $\pm 6.78 \%$ 208 in 2004 vs $26.61 \pm 14.52 \%$ in 2017) instead of a more diverse assemblage with a high abundance of Acropora spp $(9.76 \pm 5.61 \%$ vs $2.53 \pm 1.90 \%$ in 2017$)$. The cross-validated $\mathrm{R}^{2}\left(\mathrm{CV}-\mathrm{R}^{2}\right)$ from our model reaches $0.81 \pm 0.12$. The 3 dimensions 211 used were all significant and non-correlate (Table 2, Fig S1). The back calculation of structural 212 complexity captured these major shifts in community structure. High structural complexity was 213 observed in 2005 and 2006. All sites were then predicted to lose complexity corresponding to 214 the timing of COTS outbreak models present patterns of decrease and increase in rugosity, 215 matching with the biotic and abiotic changes like the COTS outbreak and the Cyclone Oli, as 216 discussed above (Fig. 5). The model also exemplifies that the resilience of structural 217 complexity differs among the thirteen reefs studied around Moorea island. In 2004, the 218 highest values of structural complexity were measured respectively at Pihaena (North), 219 Motu Ahi (East) and Haapiti (Northwest) (3.86, 3.51 and 2.92 respectively) while the 220 lowest were recorded in Maatea (Southeast), Tiahura (North) and Aroa (North) (2.26, 2212.07 and 1.81 respectively). After the disturbances in 2010, the higher values were 222 defined in Taotaha (Northwest), Afareaitu (Southeast) and Entre 2 Baies (North) (2.08, 2232.10 and 2.10 respectively) while the lowest values were documented at Haapiti 224 (Northwest), Tiahura (North) and Maatea (Southeast) (1.84, 1.66 and 1.15 respectively). 225 Finally, in 2017, the 3 lowest values were measured on the East coast (Motu Ahi, Maatea 226 and Temae with rugosity values of 2.35, 2.12 and 1.98 respectively) while the sites located 
on the northwest side (Entre 2 Baies, Tiahura and Gendron) presented the 3 higher rugosity scores (4.36, 4.31 and 3.53 respectively).

Finally, rugosity values rise to values equivalent to the first year of monitoring, during the last year of monitoring in 2017. The presence of Acropora spp. shows a significant difference between 2004 and 2017. However, no significant difference could be observed in 232 either the Pocillopora spp. presence or the rugosity score (Fig. 6). In addition, the ANOVA 233 followed by the post-hoc analysis confirmed a difference between two bunches of years according to the complexity around the island. Indeed, two profiles were highlighted: 1) one from 2004 to 2007 and 2016 to 2017 and 2) one from 2008 to 2015. These results support that the 3D complexity came back to an equilibrium four years after the Oli cyclone (Table S1).

\section{Discussion}

In this study we used a combination of methods - coral reef photogrammetry and statistical models - to test the potential to use species composition data to predict the structural complexity of coral reef assemblages. The use of the photogrammetry allowed us to obtain a three-dimensional metric of structural complexity, compared to linear metrics classically used

244 such as the chain transect (Burns et al. 2015). Photogrammetry permits us to cover $40 \mathrm{~m}^{2}$ of the 245 reef in one dive of about 90 minutes, whereas the chain method usually requires approximatively 15 minutes for a simple $20 \mathrm{~m}$ transect. However, even if the pixel size of 1.73

$247 \times 1.73 \mu \mathrm{m}$ - used for defining the complexity - is higher resolution than what is achieved using 248 chain and tape, the results have to be interpreted with cautious. Indeed, a number of studies 249 have shown photogrammetry to be error prone in a number of different ways. Lavy et al. (2015) 250 and Figueira et al. (2015) both found that branching corals and other complex growth forms 251 produce more error in photogrammetry-based estimates of complexity compared to in situ methods. Furthermore, Bryson et al. (2017) found that environmental conditions, 
postprocessing, and even taking photos underwater can impact the accuracy of 3D structure 254 estimates using photogrammetry. In addition, this model is relevant for planar parts of the reef, however, facing dropoff would be challenging. This technique requires swimming over the bottom, nevertheless, as the more the distance you add between you and the bottom, the worst the reconstruction will be. Finally, all the hidden part (not present in the photos) are not reconstructed (e.g. what is inside a hole). The latter limit causes relatively heavy consequences to define an accurate measure of the rugosity in those conditions. From a statistical point of view, Carroll et al. (2006) defined 3 different regimes of swell in Moorea which could altered the benthic composition, according to the exposure due to the side of the island. Even if these affirmations are directly observable concerning the rugosity in 2017 with our current model (lowest values on the east coast and higher values on the north coast) a mixed model would have been more relevant. Unfortunately, only 16 transects were done on the southeast side of Moorea which is not allowed us for using a mixed model. The robustness of the model would have been directly impacted by the lack of residuals (rugosity values sometimes lower than 1; Launer \& Wilkinson, 2014). As per any statistical model, the accuracy of prediction will increase with the size of the calibrating dataset. In that context, more data will likely be needed to accurately capture spatial variation.

Despite these limits, we have found a significant relationship between reef structural complexity and the composition of the benthic assemblages. Indeed 3 PCA axes were enough to accurately predict complexity with a high accuracy $\left(\mathrm{CV}-\mathrm{R}^{2}=0.81 \pm 0.12\right)$. To validate our model, we compared our values to (Kayal et al. 2017). These authors have found values at $12 \mathrm{~m}$ depth of $1.44 \pm 0.08,1.41 \pm 0.05$ and $1.70 \pm 0.03$ for Haapiti, Tiahura and Entre 2 Baies respectively. Our model suggests values for these locations of $1.75 \pm 0.50,1.68 \pm 0.47$ and 1.70 $276 \pm 0.60$ respectively. Thus, even according the huge range of the uncertainties, our results 277 highlight the potential to use statistical modeling to predict structural complexity when this 278 information is lacking. Given the importance of structural complexity in ecological functioning 
of coral reefs, the reconstruction of structural complexity is critical from long-term benthic

280 historical data, if we want to better understand and predict changes in coral reefs. For example,

281 Graham and Nash (2013) reviewed 20 studies using chain method to measure coral reef rugosity

282 in the Caribbean and found a strong negative relationship between structural complexity and

283 algal cover, a positive relationship between the structural complexity and the coral cover, and

284 a strong positive relationship between structural complexity and fish density and biomass.

285 Later, Graham et al. (2015) demonstrated that structural complexity is the main predictor of

286 coral reef recovery capacity after acute disturbance. This metric represents thus a key variable

287 of coral reef status, and apodictically exists also regarding the present day flattening of coral

288 reefs under the influence of climate change and human impacts. Back-calculating structural

289 complexity, with due caution, may be important to infer present coral reef status compared to

290 historical or quasi-pristine conditions.

291 Here, we have documented major changes in benthic assemblages across Moorea's coral

292 reefs (Berumen and Pratchett 2006; Adjeroud et al. 2018). Acropora spp. and Pocillopora spp.

293 were dominant species in 2003 (Berumen and Pratchett 2006) and this was still the case in 2004.

294 Pocillopora spp. then, Acropora spp. were affected by both COTS outbreak and the Oli cyclone

295 more than any other taxon (Kayal et al. 2012). Branching and table-shaped species belonging

296 to the genus Acropora were affected first and most heavily. Then, it was followed by those of

297 sub-branching Pocillopora. Finally, Populations of encrusting Montipora, massive Porites, and

298 other hard-coral assemblages also declined, showing a synchronized collapse with the entire

299 coral communities. From 2011 onward, benthic assemblages started to recover mainly thanks

300 to encrusting coral forms and Pocillopora spp. that is presently the dominating coral form in

301 Moorea. The current Pocillopora-dominated state may be a transitional phase, indicative of

302 either continuing degradation or recovery (Aronson et al. 2004). Our back-calculated structural

303 complexity was able to capture major changes due to COTS outbreak and Cyclone Oli, thus

304 attesting the potential to use statistical modeling when the rugosity has not been empirically 
collected. However, the status of coral reefs in 2004 when Acropora spp. was on average $\approx 10 \%$

306 and the present status (average Acropora cover $\approx 2 \%$ ) was not enough to distinguish difference

307 in back-calculated structural complexity. There are two proposed explanations for this

308 observation: (a) our model is calibrated with present-day data. Only two transects in 2017 had

309 assemblages with an Acropora cover higher than 5\% which is a consequent statistic assumption

310 according to the Acropora cover in 2004 (9.76 $\pm 5.61 \%$ in 2004 vs $2.53 \pm 1.90 \%$ in 2017). This

311 again results in an extremely cautious interpretation of the results due to a possible

312 underestimation of Acropora spp. in the past years (Aronson and Precht 2006; Alvarez-Filip et

313 al. 2009, 2011). And/or (b) Acropora and Pocillopora taxa harbored branching form and

314 similarly contribute to the complexity (Reichert et al. 2017). Thus, the complexity could be

315 rebuilt according to the coral cover underlying the different coral morphologies (Halford et al.

316 2004; Graham and Nash 2013; Richardson et al. 2017). In order to sharp our hindcasting, the

317 reproducibility of this method could allow us to find a new area with the needed information

318 (i.e. past Acropora and Pocillopora cover vs post Acropora and Pocillopora cover and past and

319 post rugosity) and to test our model. Waiting for this improvement, the CC could be enough

320 accurate to rebuild the past and to predict the complexity for the coming years. Indeed, today

321 more than ever, global coral reefs are witnessing the effects of climate changes, local impacts

322 and natural stressors. Coral bleaching is affecting global coral reefs with an unprecedented

323 frequency and intensity and the future structural complexity of coral reefs is expected to be

324 reduced by these repeated perturbations (Hughes et al. 2018; Lough et al. 2018). As a

325 consequence a loss of ecological diversity productivity is likely (Alvarez-Filip et al. 2009).

326 
333 Conflict of interest: On behalf of all authors, the corresponding author states that there 334 is no conflict of interest. 


\section{References}

Adjeroud M, Vercelloni J, Bosserelle P, Chancerelle Y, Kayal M, Iborra-Cantonnet C, Penin L, Liao V, Claudet J (2018) Recovery of coral assemblages despite acute and recurrent disturbances on a South Central Pacific reef. Sci Rep 8:8

Alvarez-Filip L, Côté IM, Gill JA, Watkinson AR, Dulvy NK (2011) Region-wide temporal and spatial variation in Caribbean reef architecture: Is coral cover the whole story? Glob Chang Biol 17:2470-2477

Alvarez-Filip L, Dulvy NK, Gill JA, Côté IM, Watkinson AR (2009) Flattening of Caribbean coral reefs: Region-wide declines in architectural complexity. Proc R Soc B Biol Sci 276:3019-3025

Aronson RB, MacIntyre IG, Wapnick CM, O'Neill MW (2004) Phase shifts alternative states and the unprecedented convergence of two reef systems. Ecol Soc Am 85:1876-1891

Aronson RB, Precht WF (2006) Conservation, precaution, and Caribbean reefs. Coral Reefs 25:441-450

Berumen ML, Pratchett MS (2006) Recovery without resilience: Persistent disturbance and long-term shifts in the structure of fish and coral communities at Tiahura Reef, Moorea. Coral Reefs 25:647-653

Bryson M, Ferrari R, Figueira W, Pizarro O, Madin J, Williams S, Byrne M (2017) Characterization of measurement errors using structure-motion and photogrammetry to measure marine habitat structural complexity. Ecol Evol 7:5669-5681

Burns J, Delparte D, Gates R, Takabayashi M (2015) Integrating structure-from-motion photogrammetry with geospatial software as a novel technique for quantifying 3D ecological characteristics of coral reefs. PeerJ 3:19

Carroll A, Harrison P, Adjeroud M (2006) Sexual reproduction of Acropora reef corals at Moorea , French Polynesia. Coral Reefs 25:93-97

Casella E, Collin A, Harris D, Ferse S, Bejarano S, Parravicini V, Hench JL, Rovere A (2017) Mapping coral reefs using consumer-grade drones and structure from motion photogrammetry techniques. Coral Reefs 36:269-275

Chazdon RL (2014) Second Growth, the promise of tropical forest regeneration in an age of deforestation.

Chazottes V, Le Campion-Alsumard T, Peyrot-Clausade M (1995) Bioerosion rates on coral reefs : interactions between macroborers, * Experimental site. Palaeogeogr Palaeoclimatol Palaeoecol 113:189-198

Figueira W, Ferrari R, Weatherby E, Porter A, Hawes S, Byrne M (2015) Accuracy and Precision of Habitat Structural Complexity Metrics Derived from Underwater Photogrammetry. Remote Sens 7:16883-16900

Friedman A, Pizarro O, Williams SB, Johnson-Roberson M (2012) Multi-Scale Measures of Rugosity, Slope and Aspect from Benthic Stereo Image Reconstructions. PLoS One 7:14

Graham NAJ, Jennings S, MacNeil MA, Mouillot D, Wilson SK (2015) Predicting climatedriven regime shifts versus rebound potential in coral reefs. Nature 518:7

Graham NAJ, Nash KL (2013) The importance of structural complexity in coral reef ecosystems. Coral Reefs 32:315-326

Gratwicke B, Speight MR (2005) Effects of habitat complexity on Caribbean marine fish assemblages. Mar Ecol Prog Ser 292:301-310

Halford A, Cheal AJ, Ryan D, Williams DM (2004) Resilience to Large-Scale Disturbance in Coral and Fish Assemblages on the Great Barrier Reef. Ecol Soc Am 85:1892-1905

Harris DL, Pomeroy A, Power H, Casella E, Rovere A, Webster JM, Parravicini V, Canavesio R, Collin A (2018) Coral reef structural complexity provides important coastal protection from waves under rising sea levels. Sci Adv 4:7

Harwin S, Lucieer A, Osborn J (2015) The Impact of the Calibration Method on the Accuracy of Point Clouds Derived Using Unmanned Aerial Vehicle Multi-View Stereopsis. Remote 
Heron SF, Maynard JA, Van Hooidonk R, Eakin CM (2016) Warming Trends and Bleaching Stress of the World's Coral Reefs 1985-2012. Sci Rep 6:14

Hill J, Wilkinson C (2004) Methods for ecological monitoring of coral reefs: A resource for managers. Version 1. Australian Institute of Marine Science, Townsville, 117.

Hobson RD (1972) Surface Roughness in Topography: A Quantitative Approach. Spatial Analysis in Geomorphology 221-245

Hoegh-Guldberg O (1999) Climate Change, coral bleaching and the future of the world' s coral reefs. Mar Freshw Res 50:839-866

Hoegh-Guldberg O, Mumby PJ, Hooten AJ, Steneck RS, Greenfield P, Gomez E, Harvell CD, Sale PF, Edwards AJ, Caldeira K, Knowlton N, Eakin CM, Iglesias-Prieto R, Muthiga N, Bradbury RH, Dubi A, Hatziolos ME (2007) Coral reefs under rapid climate change and ocean acidification. Science (80- ) 318:1737-1742

Hughes TP, Álvarez-Noriega M, Álvarez-Nomero JG, Anderson KD, Baird AH, Babcock RC, Beger M, Bellwood DR, Berkelmans R, Bridge TC, Butler IR, Byrne M, Cantin NE, Comeau S, Connolly SR, Cumming GS, Dalton SJ, Kerry JT, Kuo C, Lough JM, Hoey AS, Hobbs JA, Hoogenboom MO, Emma V, Pears RJ, Pratchett MS, Schoepf V, Simpson T, Skirving WJ, Sommer B (2017) Global warming and recurrent mass bleaching of corals. Nature 543:373-377

Hughes TP, Anderson KD, Connolly SR, Heron SF, Kerry JT, Lough JM, Baird AH, Baum JK, Berumen ML, Bridge TC, Claar DC, Eakin CM, Gilmour JP, Graham NAJ, Harrison H, Hobbs JA, Hoey AS, Hoogenboom M, Lowe RJ, Mcculloch MT, Pandolfi JM, Pratchett M, Schoepf V (2018) Spatial and temporal patterns of mass bleaching of corals in the Anthropocene. Science (80- ) 83:80-83

Hughes TP, Baird AH, Bellwood DR, Card M, Connolly SR, Folke C, Grosberg R, O. H-G, Jackson JBC, Kleypas J, Lough JM, Marshall P, Nyström M, Palumbi SR, Pandolfi JM, Rosen B, Roughgarden J (2003) Climate Change, Human Impacts, and the Resilience of Coral Reefs. Science (80- ) 301:929-933

Kayal M, Bosserelle P, Adjeroud M (2017) Bias associated with the detectability of the coraleating pest crown-of-thorns seastar and implications for reef management Subject Category : Subject Areas : R Soc Open Sci 4(8), 170396.

Kayal M, Vercelloni J, Lison de Loma T, Bosserelle P, Chancerelle Y, Geoffroy S, Stievenart C, Michonneau F, Penin L, Planes S, Adjeroud M (2012) Predator Crown-of-Thorns Starfish (Acanthaster planci) Outbreak, Mass Mortality of Corals, and Cascading Effects on Reef Fish and Benthic Communities. PLoS One 7(10), e47363.

Kohler KE, Gill SM (2006) Coral Point Count with Excel extensions (CPCe): A Visual Basic program for the determination of coral and substrate coverage using random point count methodology. Comput Geosci 32:1259-1269

Lamy T, Galzin R, Kulbicki M, Lison de Loma T, Claudet J (2016) Three decades of recurrent declines and recoveries in corals belie ongoing change in fish assemblages. Coral Reefs 35:293-302

Launer RL, \& Wilkinson GN (2014) Robustness in statistics. Academic Press.

Lavy A, Eyal G, Neal B, Keren R, Loya Y, Ilan M (2015) A quick, easy and non-intrusive method for underwater volume and surface area evaluation of benthic organisms by $3 \mathrm{D}$ computer modelling. Methods Ecol Evol 6:521-531

Leichter JJ, Alldredge AL, Bernardi G, Brooks AJ, Carlson CA, Carpenter RC, Edmunds J, Fewings, M. R, Hanson, K. M, Hench, J. L, Holbrook J, Nelson, G. E, Schmitt, R. J, Toonen, R. J, Washburn L, Wyatt, S. J (2013) Biological and physical interactons on a tropical island coral reef: transport, and retention processes on Moorea, French Polynesia. Oceanography 26:52-63

Leon JX, Roelfsema CM, Saunders MI, Phinn SR (2015) Measuring coral reef terrain roughness using "Structure-from-Motion" close-range photogrammetry. Geomorphology 
242:21-28

Lough JM, Anderson KD, Hughes TP (2018) Increasing thermal stress for tropical coral reefs : 1871 - 2017. Sci Rep 1-8

MacArthur RH, Wilson EO (1967) The Theory of Island Biogeography.

McCormick MI (1994) Comparison of field methods for measuring surface tomography and their associations with a tropical reef fish assemblage. Mar Ecol Prog Ser 112:87-96

Naughton P, Kastner R, Sandin S, Kuester F, Edwards C, Petrovic V (2015) Scaling the Annotation of Subtidal Marine Habitats. Proc 10th Int Conf Underw Networks Syst 1-5

Newman SP, Meesters EH, Dryden CS, Williams SM, Sanchez C, Mumby PJ, Polunin NVC (2015) Reef flattening effects on total richness and species responses in the Caribbean. J Anim Ecol 84:1678-1689

Van Oppen MJH, Lough JM (2009) Coral Bleaching Patterns, Processes, Causes and Consequences.

Parravicini V, Rovere A, Donato M, Morri C, Bianchi CN (2006) A method to measure threedimensional substratum rugosity for ecological studies: an example from the date-mussel fishery desertification in the north-western Mediterranean. J Mar Biol Assoc United Kingdom 86:689-690

Perry CT, Alvarez-Filip L, Graham NAJ, Mumby PJ, Wilson SK, Kench PS, Manzello DP, Morgan KM, Slangen ABA, Thomson DP, Januchowski-Hartley F, Smithers SG, Steneck RS, Carlton R, Edinger EN, Enochs IC, Estrada-Saldívar N, Haywood MDE, Kolodziej G, Murphy GN, Pérez-Cervantes E, Suchley A, Valentino L, Boenish R, Wilson M, Macdonald C (2018) Loss of coral reef growth capacity to track future increases in sea level. Nature 558:396-400

Reichert J, Backes AR, Schubert P, \& Wilke T (2017) The power of 3D fractal dimensions for comparative shape and structural complexity analyses of irregularly shaped organisms. Methods in Ecology and Evolution, 8(12), 1650-1658.

Richardson LE, Graham NAJ, Hoey AS (2017) Cross-scale habitat structure driven by coral species composition on tropical reefs. Sci Rep 7:11

Risk MJ (1972) Fish diversity on a coral reef in the virgin islands. Atoll Res Bull

Rogers A, Blanchard JL, Mumby PJ (2014) Vulnerability of coral reef fisheries to a loss of structural complexity. Curr Biol 24:1000-1005

Storlazzi CD, Dartnell P, Hatcher GA, Gibbs AE (2016) End of the chain? Rugosity and finescale bathymetry from existing underwater digital imagery using structure-from-motion (SfM) technology. Coral Reefs 35:889-894

Ullman S (1979) The interpretation of structure from motion. Proc R Soc Lond B Biol Sci 203:405-426

Westoby MJ, Brasington J, Glasser NF, Hambrey MJ, Reynolds JM (2012) "Structure-fromMotion" photogrammetry: A low-cost, effective tool for geoscience applications. Geomorphology 179:300-314

Willis TJ, Anderson MJ (2003) Structure of cryptic reef fish assemblages: relationships with habitat characteristics and predator density. Mar Ecol Prog Ser 257:209-221 


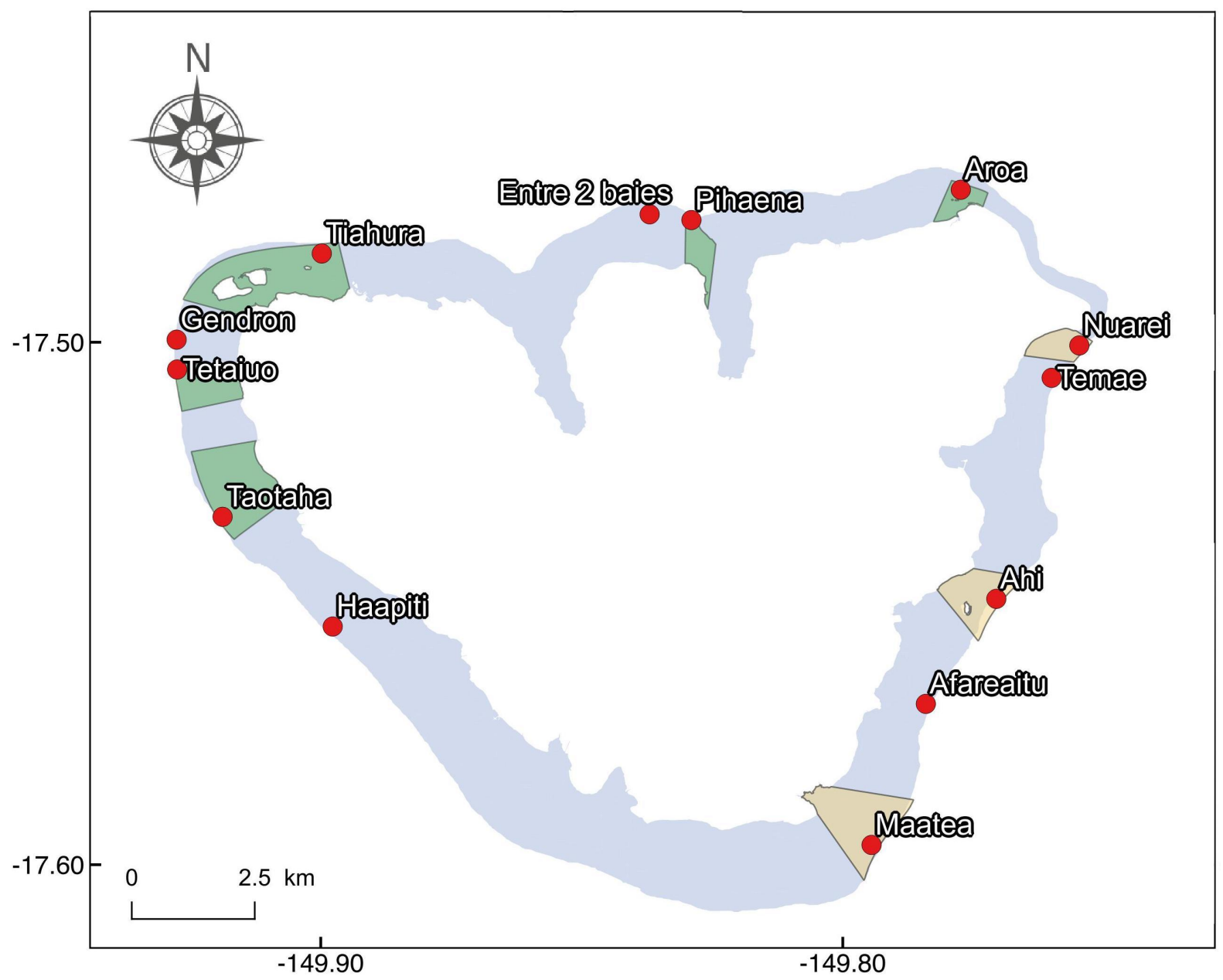

Fig. 1 Location of the 13 sites sampled each year since 2004 from 2017 of the MPA monitoring (red dots) around the island of Moorea. The 5 fully protected MPAs are highlighted in green and the restricted MPAs are highlighted in yellow. The 5 sites outside of the MPAs are controls.

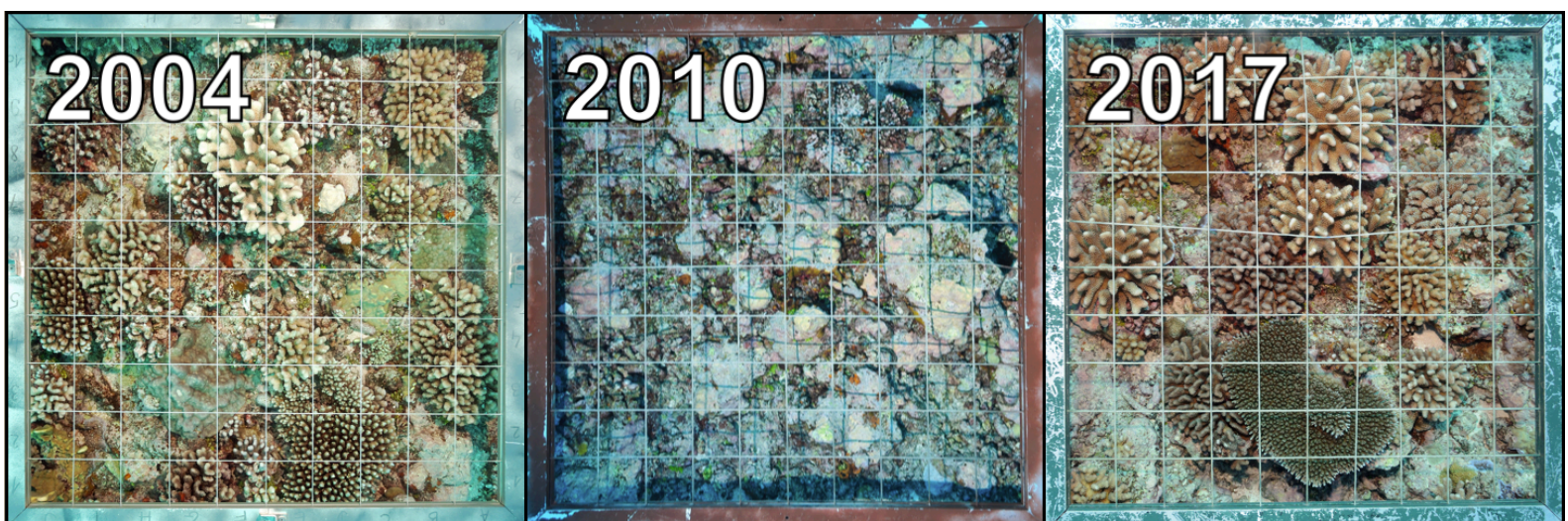

Fig. 2 Evolution of one of the twenty quadrats used to define the coral cover in Haapiti (South West of the island) before (in 2004), during (in 2010) and after (in 2017) Cyclone Oli. 

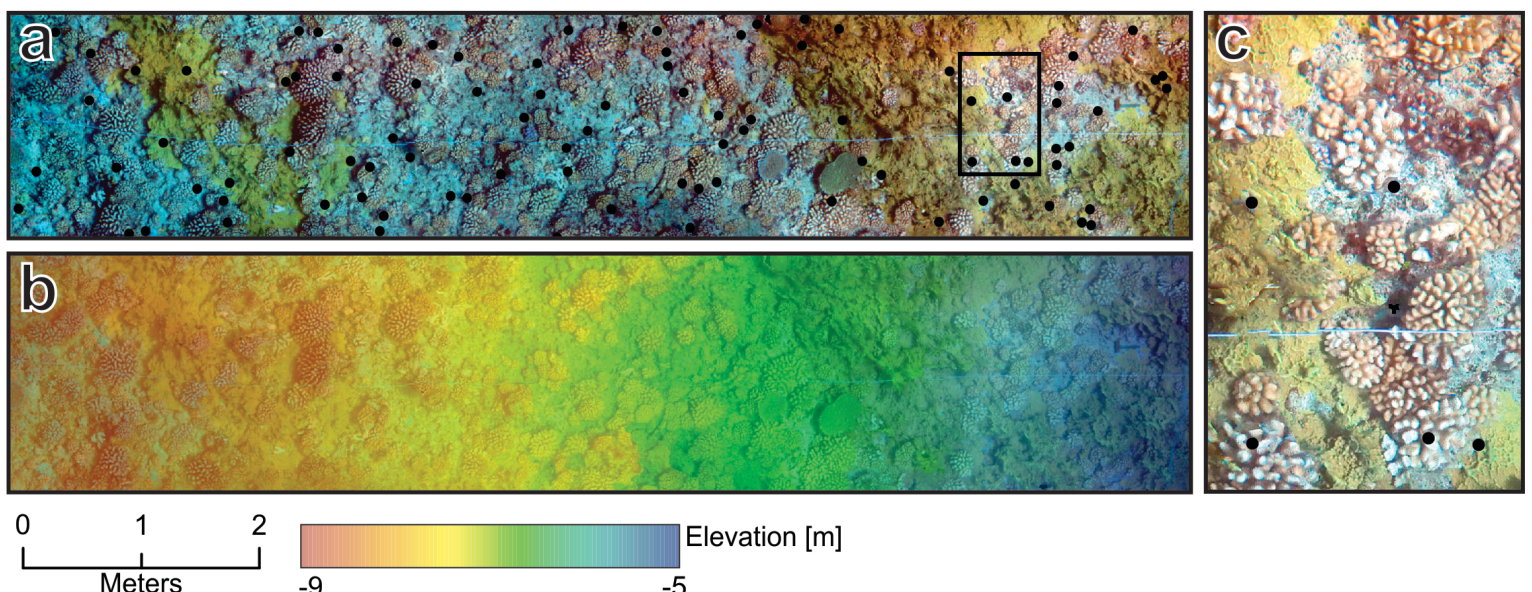

Elevation $[\mathrm{m}]$

Fig. 3 Example of results from underwater photogrammetry. a) Orthorectified photomosaic. The black dots indicate the random points where the shape classification has been carried out. b) Digital Elevation Model representing depth values (the photomosaic is kept in transparency in the background). c) Detail of the photomosaic.

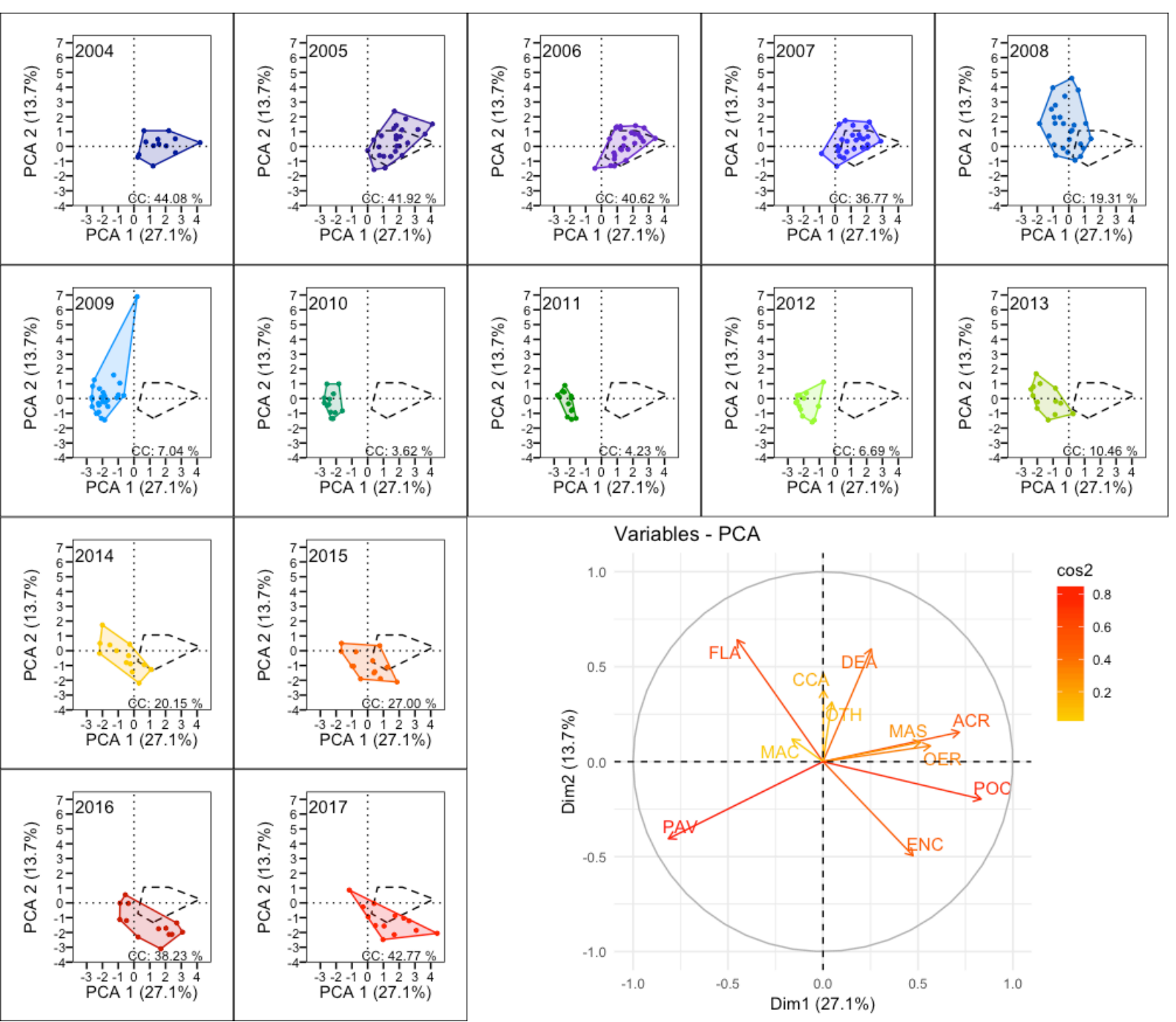

Fig. 4 Principal Components Analysis (PCA) using the 11 morpho-species respecting the code as follows: ACR - Acropora spp; CCA - Crustose Coralline Algae; DEA - Dead Coral; ENC Encrusting Corals; FLA - Flat (Sand or Mud); MAC - Macroalgae; MAS - Massive corals; OER 
- Other Erects Forms; OTH - Others (Sponges or benthic species); PAV - Pavement; and POC

511 - Pocillopora spp. The PCA was used year by year from 2004 to 2017 and the coral cover (CC)

512 is written at the bottom right of each box. The coral community in 2004 is referred as model in

513 black dashed lines each year.

514

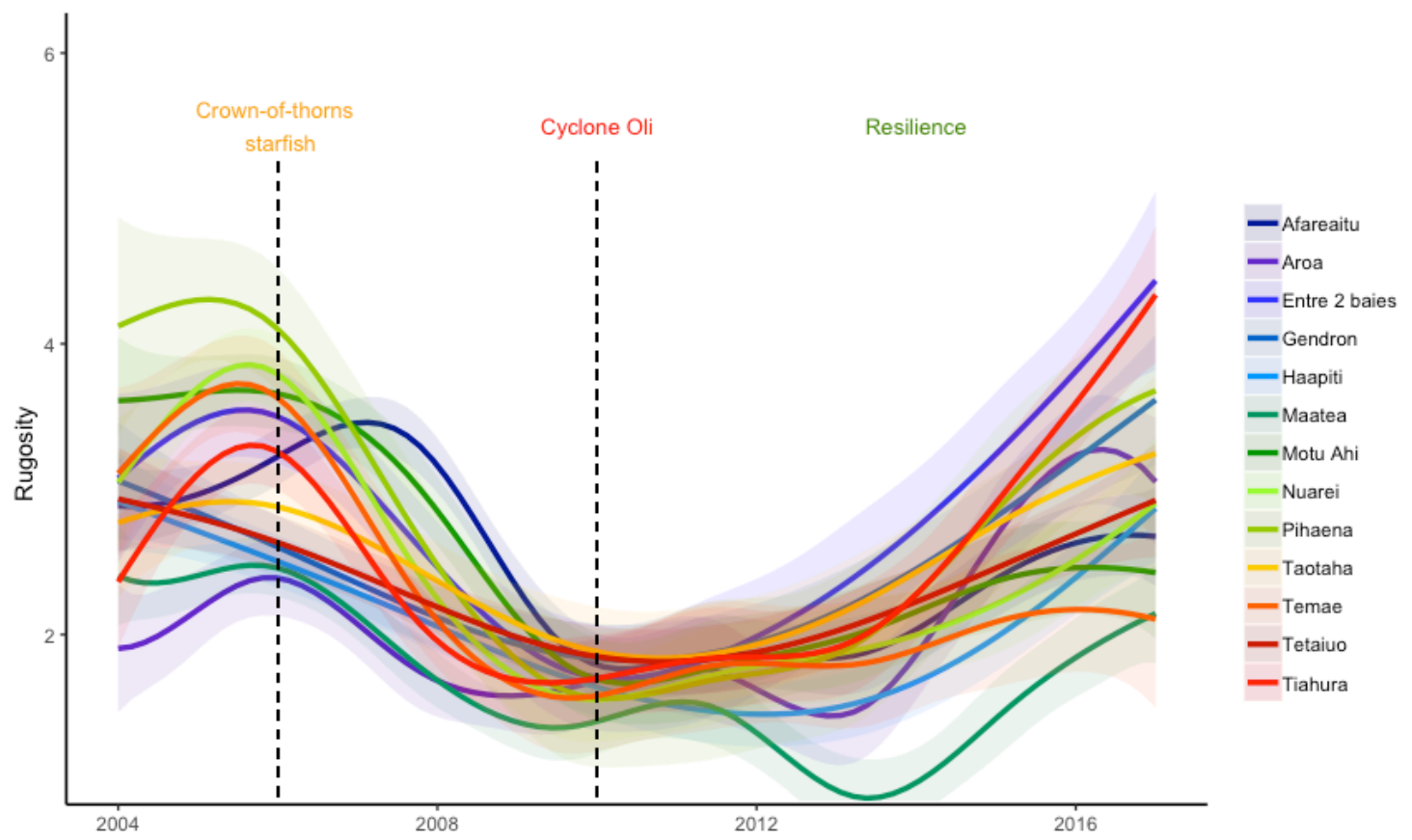

Fig. 5 Rugosity reconstruction from 2004 to 2017 according to the average model and according to the 13 sites around the island of Moorea. Both biologic invasion and extreme climatic weather events are shown for respectively 2006 and 2010.

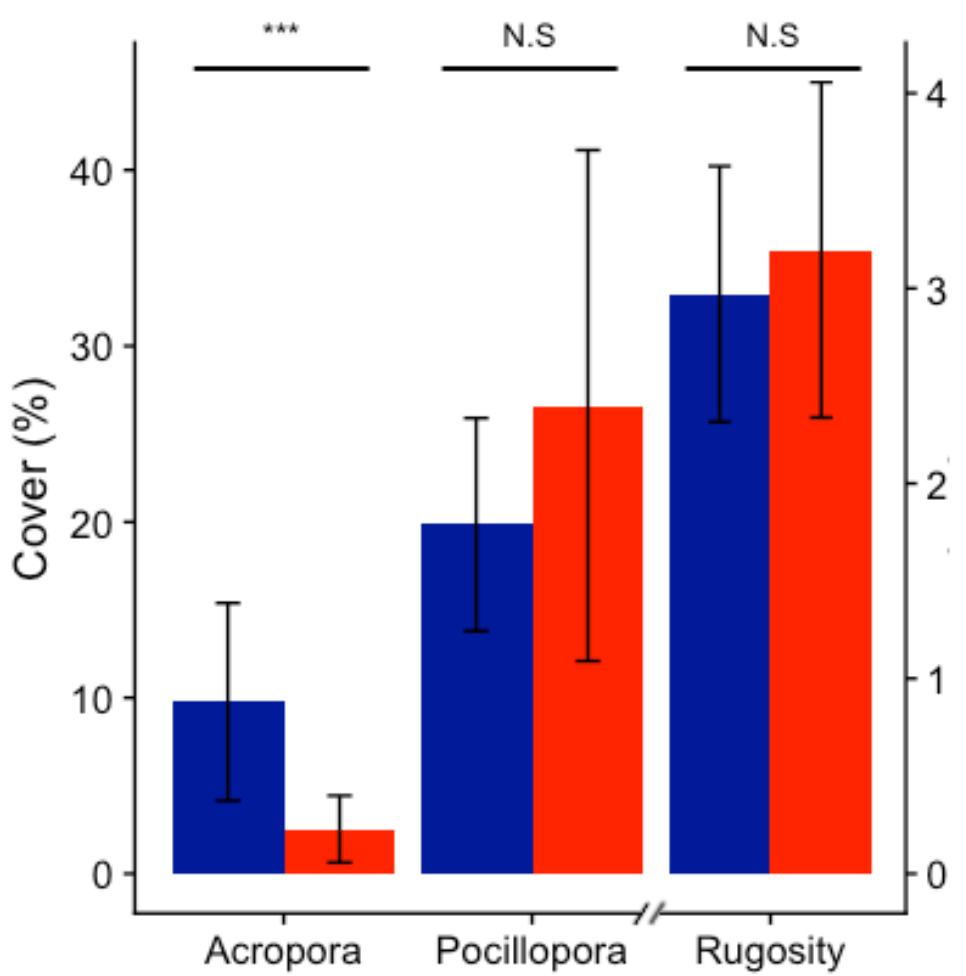

Fig. 6 Difference between the Acropora and the Pocillopora cover (\%) on the left, and the difference in rugosity (index) on the right. The dark blue color represents 2004 instead of 2017 is representing in red. The p-value is represented on the top of each barplot according to the 
significant $\mathrm{R}$ code $(* * *$ highly significant $(<0.001), * *$ very significant $(<0.01)$, * significant $(<0.05)$, almost significant $(<0.1)$, N.S non-significant; threshold: $\mathrm{p}$-value $=0.05)$

Tab. 1 Categories of shape classification defined and used to rebuild the rugosity these last 14 years. 9 variables are morphologic instead a distinction at the genus level is done for Acropora spp. and Pocillopora spp. The CCA was differentiated from the pavement according to their extension: when this later was higher than $100 \mathrm{~cm}^{2}$, which corresponds to a projected surface of a circle of radius of 5-6 cm it was considered as CCA rather than pavement. The dead corals category understands rubbles and cobbles. The flattening category represents sand or mud substrate. The categories Encrusting, Other Erect Forms and Massive represent different coral morphologies. Finally, the others category represents mostly benthic organism like echinoid or even sponges.
ACR Acropora spp.
CCA Coralline Crustose Algae
DEA Dead corals
ENC Encrusting corals
FLA Flat (Mud, Sand)
MAC Macroalgae
MAS Massive corals
OER Corals with other erects forms
OTH Other (like echinoid)
PAV Pavement
POC Pocillopora spp.

Tab. 2 Coefficients and standard error for each parameter according to best model defined: Rugosity $\sim \operatorname{Dim} 1+\operatorname{Dim} 3+\operatorname{Dim} 5\left(\mathrm{AIC}=71.776\right.$ and $\left.\mathrm{R}^{2}=0.81 \pm 0.12\right)$. The $\mathrm{p}$-value represents the significance of each parameters according to the $\mathrm{R}$ code (*** highly significant $(<0.001)$, **very significant $(<0.01), *$ significant $(<0.05)$, almost significant $(<0.1)$, N.S nonsignificant; threshold: $\mathrm{p}$-value $=0.05$ )

\begin{tabular}{lccc}
\hline & Estimate & Standard Error & p-value \\
\hline Intercept & 1.65970 & 0.14616 & $1.08 \mathrm{e}-15(* * *)$ \\
Dimension 1 & 0.53283 & 0.08602 & $9.48 \mathrm{e}-08(* * *)$ \\
Dimension 3 & 0.41917 & 0.07003 & $2.03 \mathrm{e}-07(* * *)$ \\
Dimension 5 & -0.15003 & 0.06090 & $1.71 \mathrm{e}-02(*)$ \\
\hline
\end{tabular}




\section{Appendix}

Tab. S1 Post Hoc (Tukey HSD) matrix for testing the rugosity difference according to each year combination. The P-value (threshold: 0.05 ) for each combination is written in the matrix 550 data as follows. The red values are significantly differents and the blue values are not.

\begin{tabular}{|c|c|c|c|c|c|c|c|c|c|c|c|c|c|c|}
\hline & 2004 & 2005 & 2006 & 2007 & 2008 & 2009 & 2010 & 2011 & 2012 & 2013 & 2014 & 2015 & 2016 & 2017 \\
\hline 2004 & 1,00 & & & & & & & & & & & & & \\
\hline 2005 & 0.98 & 1.00 & & & & & & & & & & & & \\
\hline 2006 & 0.96 & 1.00 & 1.00 & & & & & & & & & & & \\
\hline 2007 & 1.00 & 0.87 & 0.80 & 1.00 & & & & & & & & & & \\
\hline 2008 & 0.04 & 0.00 & 0.00 & 0.00 & 1.00 & & & & & & & & & \\
\hline 2009 & 0.00 & 0.00 & 0.00 & 0.00 & 0.93 & 1.00 & & & & & & & & \\
\hline 2010 & 0.00 & 0.00 & 0.00 & 0.00 & 0.96 & 1.00 & 1.00 & & & & & & & \\
\hline 2011 & 0.00 & 0.00 & 0.00 & 0.00 & 0.95 & 1.00 & 1.00 & 1.00 & & & & & & \\
\hline 2012 & 0.00 & 0.00 & 0.00 & 0.00 & 0.98 & 1.00 & 1.00 & 1.00 & 1.00 & & & & & \\
\hline 2013 & 0.01 & 0.00 & 0.00 & 0.00 & 1.00 & 1.00 & 1.00 & 1.00 & 1.00 & 1.00 & & & & \\
\hline 2014 & 0.11 & 0.00 & 0.00 & 0.03 & 1.00 & 1.00 & 0.99 & 0.99 & 1.00 & 1.00 & 1.00 & & & \\
\hline 2015 & 0.91 & 0.05 & 0.04 & 0.81 & 1.00 & 0.20 & 0.31 & 0.30 & 0.35 & 0.51 & 0.98 & 1.00 & & \\
\hline 2016 & 1.00 & 1.00 & 0.99 & 1.00 & 0.01 & 0.00 & 0.00 & 0.00 & 0.00 & 0.00 & 0.05 & 0.80 & 1.00 & \\
\hline 2017 & 1.00 & 1.00 & 1.00 & 1.00 & 0.00 & 0.00 & 0.00 & 0.00 & 0.00 & 0.00 & 0.00 & 0.34 & 1.00 & 1.00 \\
\hline
\end{tabular}

551

552

553

554

555

556

Fig. S1 Analysis of the residuals (fitted values vs observations) from the total model: Rugosity $\sim \operatorname{Dim} 1+\operatorname{Dim} 2+\operatorname{Dim} 3+\operatorname{Dim} 4+\operatorname{Dim} 5\left(\mathrm{AIC}=71.8, \mathrm{R}^{2}=0.78 \pm 0.08\right)$ on the left and the best model Rugosity $\sim \operatorname{Dim} 1+\operatorname{Dim} 3+\operatorname{Dim} 5\left(\mathrm{AIC}=73.6, \mathrm{R}^{2}=0.81 \pm 0.12\right)$ on the right.
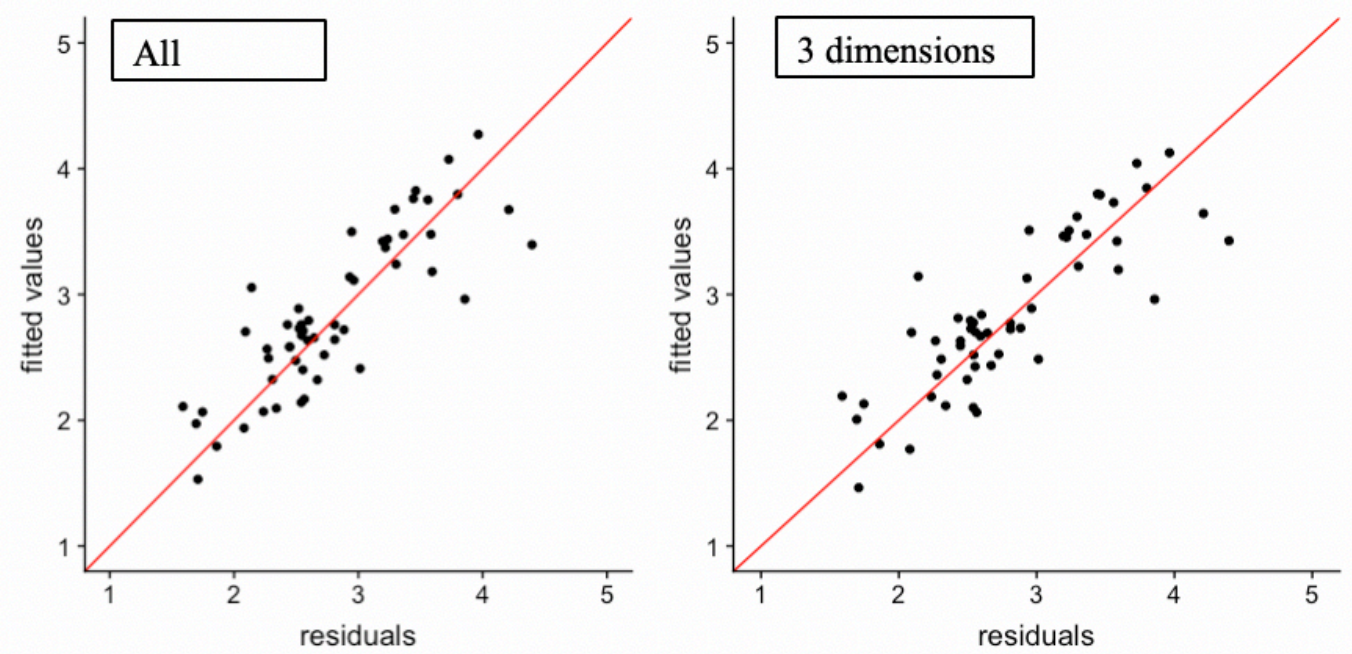


\section{Annex}

Annex S1 Report from Agisoft Photoscan for one site, detailing the settings used for the processing of underwater photos.

\section{Survey Data}

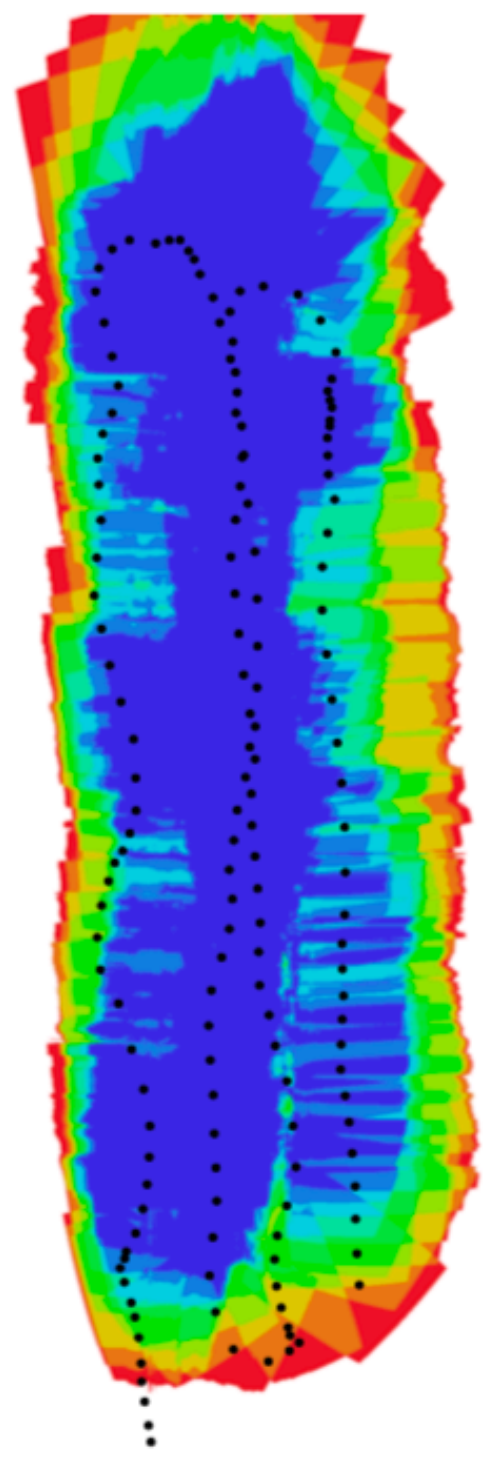

Fig. 1 Camera locations and image overlap

Number of images: $\quad 157$

Flying attitude: $\quad 2.56 \mathrm{~m}$

Ground resolution: $\quad 0.53 \mathrm{~mm} / \mathrm{pix}$

Coverage area:
Camera stations:

157

Tie points:

Projections:

139.838

383.598

Reprojection error: 1.88 pix

570 Tab. 1 Cameras

\begin{tabular}{|l|l|l|l|}
\hline Camera Model & Resolution & Focal Length & Pixel Size \\
\hline HERO4 Black $(3 \mathrm{~mm})$ & $4000 \times 3000$ & $3 \mathrm{~mm}$ & $1.73 \times 1.73 \mathrm{um}$ \\
\hline
\end{tabular}




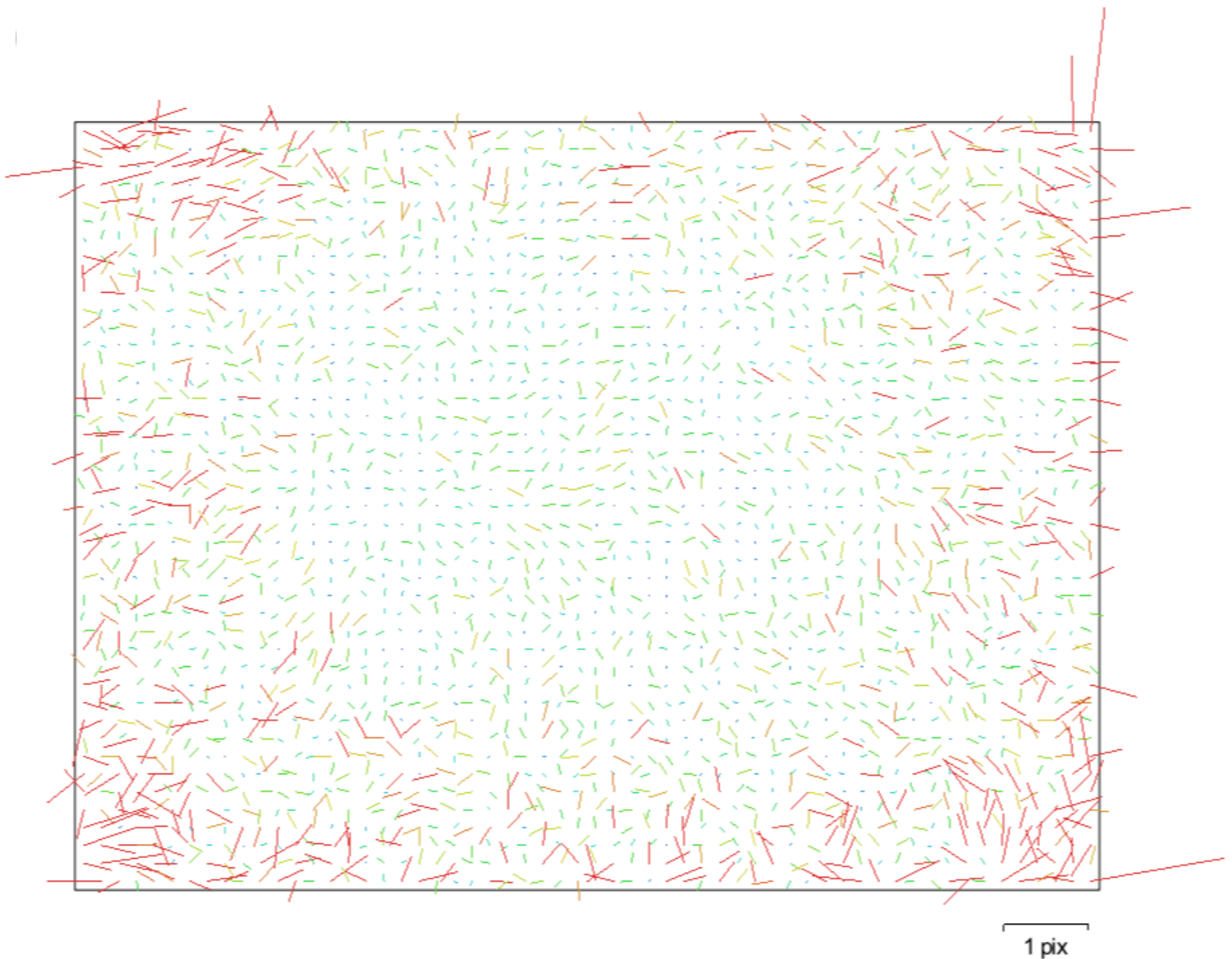

574

575

576

577

578

Fig. 2 Image residuals for HERO4 Black (3 mm).

HERO4 Black (3mm)

157 images

Resolution

4000x3000

Focal length

$3 \mathbf{~ m m}$

Frame

4666.42

4666.42

Fy:

0.223613

$\mathrm{K} 2$ :

0.373779

K3:

1.24196

K4:
Pixel size

$1.73 \times 1.73 \mu \mathrm{m}$

Skew:

Cx:

Cy:

P1:

P2:

P3:

P4:
Precalibrated

No

0

2005.25

1486.48

0.00194777

$-0.00200162$

0

0

\section{Ground Control Points}




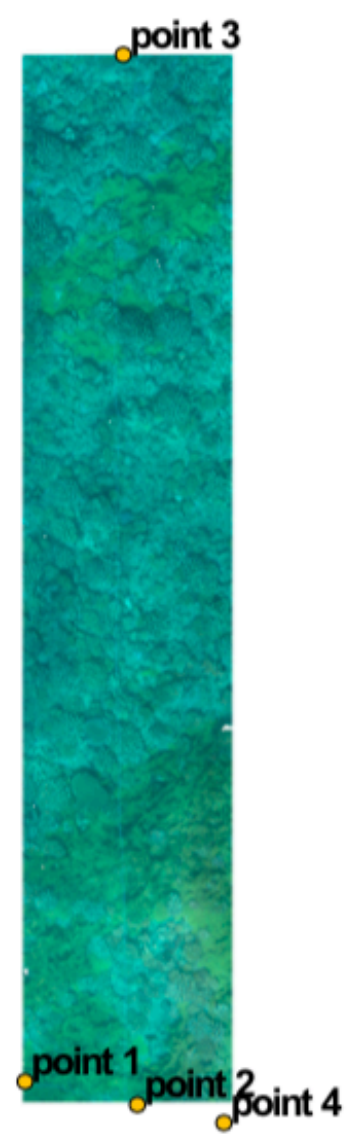

Fig. 3 GCP locations

589 Tab. 2 Control points

\begin{tabular}{|l|l|l|l|l|l|}
\hline Label & XY error(m) & Z error (m) & Error (m) & Projections & Error (pix) \\
\hline point 1 & 0.206298 & -0.0677987 & 0.217153 & 13 & 1.992 \\
\hline point2 & 0.0963633 & 0.0426041 & 0.105361 & 16 & 1.153 \\
\hline point3 & 0.039409 & $3.96756 \mathrm{e}-05$ & 0.039409 & 17 & 0.051 \\
\hline point 4 & 0.205045 & 0.0251539 & 0.206582 & 9 & 0.044 \\
\hline Total & $\mathbf{0 . 1 5 4 4 6 8}$ & $\mathbf{0 . 0 4 1 9 6 5 7}$ & $\mathbf{0 . 1 6 0 0 6 7}$ & & $\mathbf{1 . 1 5 1}$ \\
\hline
\end{tabular}



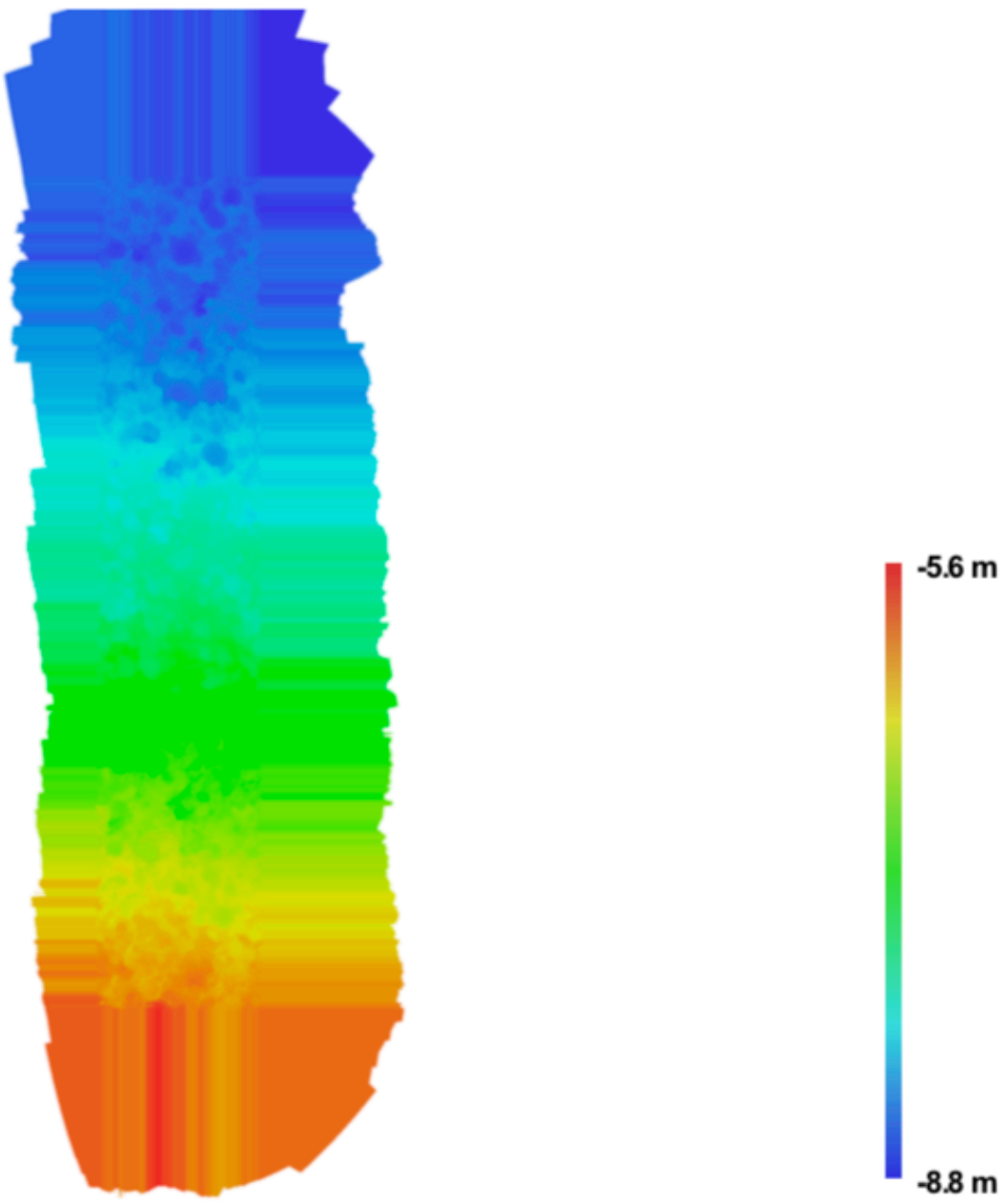

Fig. 4 Reconstructed digital elevation model.

596

Resolution: $\quad 1.06 \mathrm{~mm} / \mathrm{pix}$

597

Point density: 889956 points per sq $\mathrm{m}$

598 


\section{General}

Cameras

157

Aligned cameras

157

Markers

4

Coordinate system

Local Coordinates

Point Cloud

Points

139,838 of 221,231

RMS reprojection error

0.382302 (1.88392 pix)

Max reprojection error

6.30304 (30.1948 pix)

Mean key point size

Effective overlap

5.32459 pix

2.94411

Alignment parameters

Accuracy

High

Pair preselection

Disabled

Key point limit

40,000

Tie point limit

Constrain features by mask

4,000

Matching time

Alignment time

Optimization parameters

No

17 minutes 46 seconds

3 minutes 10 seconds

Parameters

f, cx, cy, k1-k3, p1, p2

Optimization time

5 seconds

Dense Point Cloud

Points

$72,229,238$

Reconstruction parameters

Quality

Depth filtering

Processing time

High

Aggressive

8 minutes 29 seconds

\section{Model}

Faces

$4,815,282$

Vertices

$2,417,898$

Reconstruction parameters

Surface type

Source data

Interpolation

Quality

Depth filtering

Face count

Processing time

DEM

Size

Coordinate system

Reconstruction parameters

Source data

Interpolation

Orthomosaic

Size

Coordinate system

Channels

Blending mode

Reconstruction parameters

Surface

Enable color correction

Arbitrary

Dense

Enabled

High

Aggressive

$4,815,282$

4 hours 29 minutes

$1,886 \times 9,433$

Local Coordinates

Dense cloud

Enabled

$3,773 \times 18,867$

Local Coordinates

3, unit8

Mosaic

Mesh

No 